\title{
Ventral Pallidum Is the Primary Target for Accumbens D1 Projections Driving Cocaine Seeking
}

\author{
Thibaut R. Pardo-Garcia, ${ }^{2}$ CConstanza Garcia-Keller, ${ }^{1}$ Tiffany Penaloza, ${ }^{1}$ Christopher T. Richie, ${ }^{3}$ James Pickel, ${ }^{4}$ \\ Bruce T. Hope, ${ }^{3}$ Brandon K. Harvey, ${ }^{3}{ }^{-}$Peter W. Kalivas, ${ }^{1}$ and ${ }^{-}$Jasper A. Heinsbroek ${ }^{1}$ \\ ${ }^{1}$ Department of Neuroscience, Medical University of South Carolina, Charleston, South Carolina 29425, ${ }^{2}$ Department of Neuroscience, University of \\ Michigan, Ann Arbor, Michigan 48109, ${ }^{3}$ Intramural Research Program, National Institute on Drug Abuse, Baltimore, MD 21224, and ${ }^{4}$ National Institute of \\ Mental Health, Bethesda, MD 20892
}

Outputs from the nucleus accumbens (NAc) include projections to the ventral pallidum and the ventral tegmental area and subtantia nigra in the ventral mesencephalon. The medium spiny neurons (MSN) that give rise to these pathways are GABAergic and consist of two populations of equal number that are segregated by differentially expressed proteins, including D1- and D2-dopamine receptors. Afferents to the ventral pallidum arise from both D1- and D2-MSNs, whereas the ventral mesencephalon is selectively innervated by D1-MSN. To determine the extent of collateralization of D1-MSN to these axon terminal fields we used retrograde labeling in transgenic mice expressing tdTomato selectively in D1-MSN, and found that a large majority of D1-MSN in either the shell or core subcompartments of the accumbens collateralized to both output structures. Approximately $70 \%$ of D1-MSNs projecting to the ventral pallidum collateralized to the ventral mesencephalon, whereas $>90 \%$ of mesencephalic D1-MSN afferents collateralized to the ventral pallidum. In contrast, $<10 \%$ of dorsal striatal D1-MSNs collateralized to both the globus pallidus and ventral mesencephalon. D1-MSN activation is required for conditioned cues to induce cocaine seeking. To determine which D1-MSN projection mediates cued cocaine seeking, we selectively transfected D1-MSNs in transgenic rats with an inhibitory Gi-coupled DREADD. Activation of the transfected Gi-DREADD with clozapine-N-oxide administered into the ventral pallidum, but not into the ventral mesencephalon, blocked cue-induced cocaine seeking. These data show that, although accumbens D1-MSNs largely collateralize to both the ventral pallidum and ventral mesencephalon, only D1-MSN innervation of the ventral pallidum is necessary for cue-induced cocaine seeking.

Key words: accumbens; DREADD; indirect pathway; relapse; retrograde tracing; transgenic

Significance Statement

Activity in D1 dopamine receptor-expressing neurons in the NAc is required for rodents to respond to cocaine-conditioned cues and relapse to drug seeking behaviors. The D1-expressing neurons project to both the ventral pallidum and ventral mesencephalon, and we found that a majority of the neurons that innervate the ventral pallidum also collateralize to the ventral mesencephalon. However, despite innervating both structures, only D1 innervation of the ventral pallidum mediates cue-induced cocaine seeking.

\section{Introduction}

NAc neurons are the main target for cortical, allocortical, and thalamic information entering ventral basal ganglia circuitry

Received Nov. 2, 2018; revised Dec. 11, 2018; accepted Dec. 21, 2018.

Author contributions: C.G.-K.,P.W.K., and J.A.H. edited the paper; J.A.H. wrote the first draft of the paper. P.W.K. and J.A.H. designed research; T.R.P.-G., C.G.-K., T.P., and J.A.H. performed research; C.T.R., J.P., B.T.H., and B.K.H. contributed unpublished reagents; P.W.K. and J.A.H. analyzed data.

This work was supported by National Institutes of Health Grants DA00396 and DA012513, National Science Foundation Grant OIA-1539034, and partially supported by the Intramural Research Programs at the National Institute on Drug Abuse and the National Institute of Mental Health.

We thank the National Institute of Drug Abuse (NIDA) Drug Supply Program for providing cocaine hydrochloride and clozapine-N-oxide, and Julie Necarsulmer, Heather Baldwin, Pyry Koivula, Yajun Zhang, the NIDA Optogenetics and Transgenic Technology Core and the NIDA Histology Core for technical assistance with the production of the D1-Cre rats.
(Groenewegen et al., 1999). As such, these neurons are critical mediators of goal-directed behavior, reward, and reinforcement learning (Floresco, 2015). The NAc can be subdivided into a central core (NAcore) and surrounding shell (NAshell) subregion based on the expression of different histochemical markers, and on distinct and topographically organized afferent input (Haber, 2011; Scofield et al., 2016). The main efferent projections from the accumbens to the ventral pallidum (VP) and ventral mesen- 
cephalon are also organized topographically (Heimer et al., 1991). NAcore neurons preferentially innervate the dorsolateral compartment of the VP, and the medial substantia nigra (SN) in the ventral mesencephalon (Heimer et al., 1991; Kupchik et al., 2015). In turn, NAshell neurons innervate the ventral VP, dopaminergic, and GABAergic neurons in the medial ventral tegmental area (VTA), and laterally located VTA GABA neurons (Heimer et al., 1991; Yang et al., 2018).

The majority of neurons in the NAc (90\%-95\%) are medium spiny projection neurons (MSNs), which consist of two subpopulations with distinct functions that express different dopamine receptors (Gerfen et al., 1990; Saunders et al., 2018). Dopamine D1 receptor-expressing MSNs (D1-MSNs) positively regulate motivated states and motor activity via the canonical "direct pathway," a disynaptic transpallidal output pathway that disinhibits basal ganglia output structures (Gerfen and Surmeier, 2011). On the other hand, dopamine D2 receptor-expressing projection neurons (D2-MSNs) negatively regulate motivation and motor activity and give rise to a multisynaptic basal ganglia pathway that inhibits downstream brain regions (Gerfen and Surmeier, 2011; Smith et al., 2013). Supporting this model, D1and D2-MSNs in the dorsal striatum project into mostly separate basal ganglia circuits. However, NAc D1- and D2-MSNs both innervate the VP, and these neurons give rise to both direct and indirect transpallidal projections (Robertson and Jian, 1995; Lu et al., 1998; Kupchik et al., 2015; Creed et al., 2016; Matsui and Alvarez, 2018).

Almost all VP neurons are innervated by D2-MSN, and at least $50 \%$ of VP neurons receive D1-MSN inputs (Kupchik et al., 2015). Despite the absence of a strict direct and indirect pathway organization of accumbens D1-MSN outputs, activity in accumbens D1-MSNs remains necessary for motivated behavior, including cue-induced drug seeking (Creed et al., 2016; Heinsbroek et al., 2017; Gallo et al., 2018). The circuitry confound created by the presence of both direct and indirect accumbens D1-MSN projections is augmented by retrograde tracing and single neuron axon tracing demonstrating that some accumbens neurons collateralize between the VP and VTA/SN (Robertson and Jian, 1995; Tripathi et al., 2010). However, the proportion of collateralizing D1-MSNs is not known. Furthermore, it remains unknown whether all D1-VP inputs originate from D1-VTA/SN projecting neurons, or whether some D1-MSNs exclusively innervate the VP and not the VTA/SN. Importantly, a high degree of collateralization between VP and VTA/SN may warrant the reinterpretation of effects observed following projection specific D1-MSN manipulations because observed effects may depend on the VP, the VTA/SN, or both. For example, optogenetically stimulating VP axons may inadvertently cause effects in the VTA/SN through the antidromic activation of axon collaterals (Yizhar et al., 2011).

We used a combination of circuit tracing strategies to investigate the extent of collateralization between the striatomesencephalic and striatopallidal projections of accumbens D1MSNs. Because we found that almost all D1-MSNs projecting to the VTA/SN send collaterals to the VP, we used chemogenetic terminal silencing to functionally dissect the role of D1-VP and D1-SN projections from NAcore during reinstatement of cocaine seeking. Surprisingly, we found that only activity in the accumbens D1-VP, not in the D1-SN pathway, was necessary for cocaine seeking. These data indicate that synapses from the same neurons can mediate different functions between output structures, and identify a critical role for the D1-VP pathway underlying motivated cocaine seeking.

\section{Materials and Methods}

Animals and housing. Male and female mice and rats were bred at the Medical University of South Carolina in a temperature- and humiditycontrolled room under reverse light schedule conditions (8:00 A.M. to 8:00 P.M.). Dopamine D1 receptor tdTomato reporter mice (Shuen et al., 2008) were obtained from Vanderbilt University and crossed with WT mice (C57BL/6J, The Jackson Laboratory). Transgenic Long-Evans D1-iCre transgenic rats (LE-Tg ${ }^{\text {Drdla-iCre-3Ottc }}$ ) were obtained from the National Institute on Drug Abuse transgenic animal core facility, and crossed with WT Long-Evans rats (Charles River).

D1-iCre transgenic rats. To generate Drd1-iCre rats (D1-iCre), a bacterial artificial chromosome (BAC) containing the rat Drdla gene (CH230-115J9) was obtained from the Children's Hospital Oakland Research Institute, and recombined to replace the start codon of Drd1 $a$ with a $1.3 \mathrm{~kb}$ cassette containing iCre (improved Cre recombinase) and the polyadenylation signal from the gene for bovine growth hormone (Warming et al., 2005). This BAC was injected into the pronuclei of fertilized Long Evans rat embryos by the National Institute of Mental Health Transgenic Core, which were transferred to pseudopregnant female rats and carried to term, ultimately resulting in seven independent, phenotypically positive Drdla::iCre lines. The line "LE-Tg(Drd1aiCre)3Ottc" has a single copy of the transgene per haploid genome as determined by droplet digital PCR and is registered at the Rat Genome Database (RGD: 10412325) and deposited at the Rat Resource and Research Center (RRRC \#767; University of Missouri, Columbia MO, USA).

Drugs. Cocaine hydrochloride (National Institute on Drug Abuse) was dissolved in sterile saline and filtered before use. For intraperitoneal injections, clozapine-N-oxide (CNO; National Institute on Drug Abuse drug supply program) was dissolved in $100 \%$ DMSO and diluted to a 10 $\mathrm{mg} / \mathrm{ml}$ solution using sterile saline (final vehicle solution: $5 \%$ DMSO and saline). For microinjections, $\mathrm{CNO}$ (Abcam) was dissolved at $1 \mathrm{~mm}$ in sterile aCSF (in mm as follows: $126 \mathrm{NaCl}, 1.4 \mathrm{NaH}_{2} \mathrm{PO}_{4}, 25 \mathrm{NaHCO}_{3}, 1.2$ $\left.\mathrm{MgCl}_{2}, 2.4 \mathrm{CaCl}_{2}, 2.5 \mathrm{KCl}\right)$.

Retrograde tracing. Fluorogold (FG) was iontophoretically deposited into the mouse VP (anteroposterior [AP]: 0.3; mediolateral [ML]: between 1.3 and 1.5 ; dorsoventral [DV]: -5 ) or globus pallidus (GP; AP: -0.2 ; ML: 1.7; DV: -4.0$)$ using glass micropipettes ( $\sim 15 \mu \mathrm{m}$ tip) and an iontophoresis pump (BAB-501, Kation Scientific). FG deposit placements in the VP were varied (ML: between 1.3 and 1.5) to retrogradely label NAcore or NAshell neurons. For iontophoresis, the following parameters were used: current: $3 \mu \mathrm{A}$; pulse width: $7 \mathrm{~s}$; duration: $5 \mathrm{~min}$; and iontophoresis was terminated by reversing the polarity of the circuit. Retrobeads (Lumafluor) were pressure-injected into ventral mesencephalon nuclei (VTA: AP - 2.8; ML 0.5; DV - 4.6; medial SN: AP - 2.8; ML 1.3; DV -4.8; lateral SN: AP -2.8; ML 1.7; DV - 4.8) using glass micropipettes (tip: $\sim 20 \mu \mathrm{m}$ ) and an automated nanoliter injection system (NanoJect, Drummond Scientific). After injections, pipettes were left in place for an additional $10 \mathrm{~min}$ and then slowly retracted. Animals were given at least $10 \mathrm{~d}$ to allow for the retrograde transport of tracers into the soma of NAc and dorsal striatal neurons, and were then transcardially perfused with ice-cold saline followed by a $10 \%$ phosphate buffered formalin-saline solution.

Immunohistochemistry. Brains were postfixed at $4^{\circ} \mathrm{C}$ in $10 \%$ formalin overnight, followed by a $2 \mathrm{~d}$ incubation in cryoprotectant $(30 \%$ sucrose in PBS) at $4^{\circ} \mathrm{C}$. Afterward, brains were flash-frozen on dry ice and sliced into $50 \mu \mathrm{m}$ sections on a cryostat. For immunohistochemical staining, free-floating sections were treated with blocking solution $(0.25 \%-0.5 \%$ Triton X-100, 2.5\% BSA, 5\% normal goat serum, in PBS) for $2 \mathrm{~h}$ at room temperature. Afterward, brains were incubated overnight into blocking solution containing the following primary antibodies: mouse anti-NeuN (1:1000; Millipore MAB-377; RRID:AB_2298772), rabbit anti-substance P (1:1000, Immunostar \#20064, RRID:AB_572266), mouse anti-TH (1: 10,000, Immunostar \#22941, RRID:AB_572268), rabbit anti-FG (1:1000; Fluorochrome; RRID:AB_2314408), and rabbit anti-dsRed (1:1000; Clontech \#632496; RRID:AB_10013483). Finally, sections were stained using standard AlexaFluor-conjugated secondary antibodies (1:500; Thermo Fisher Scientific), or using a peroxidase-mediated DAB stain. 
A
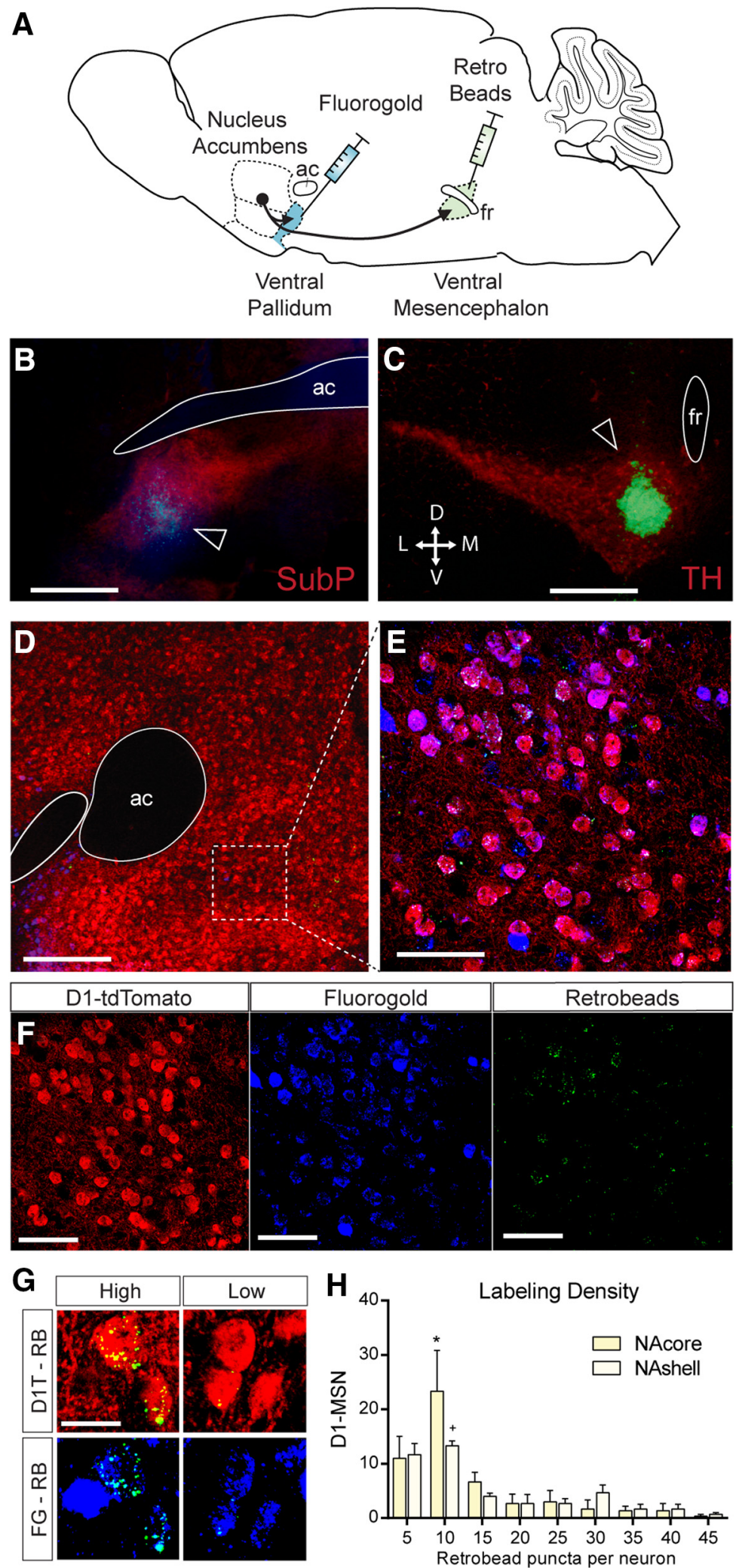

Fluorogold

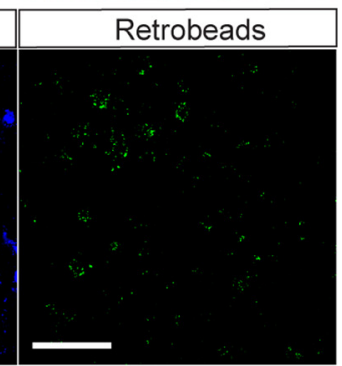

G

H

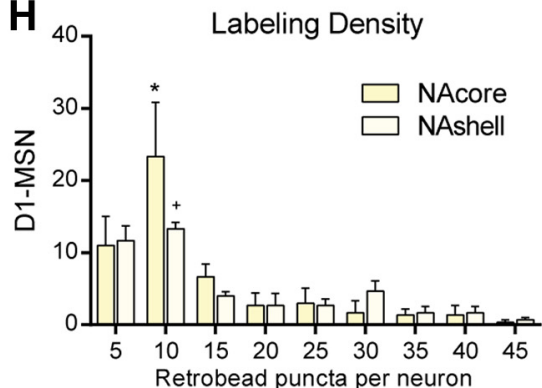

Figure 1. Examples of retrograde tracer localized to ventromedial NAcore D1-MSNs. A, Graphical representation of the tracing experiment. FG was iontophoretically deposited into the VP, and retrobeads were pressure-injected into the ventral mesencephalon. $\boldsymbol{B}$, Example of FG deposit into the lateral VP (blue). Image was counterstained with substance P immunohistochemistry (red) to delineate the VP. ac, Anterior commissure. Scale bar, $1 \mathrm{~mm}$. C, Example injection of retrobeads to the medial VTA (green spot next to fasciculus retroflexus [fr]]). Image counterstained with tyrosine hydroxylase stain to delineate the VTA and SNpc. Scale bar, $1 \mathrm{~mm}$. D, NAc section containing D1-MSNs that express the fluorescent reporter tdTomato and the retrograde tracers FG and retrobeads. Scale bar, $1 \mathrm{~mm}$. E, Higher-magnification image taken from the NAc shows colocalization of retrobeads (green), FG (blue), and tdTomato (red) to the same neurons indicating substantial collateralization between the D1-MSN projections to the VP and VM. Scale bar, $50 \mu \mathrm{m}$. $\boldsymbol{F}$, Individual fluorescent labels from the magnified image stack shown in $\boldsymbol{E}$. $\boldsymbol{G}$, Examples of high and
Fluorescently labeled sections were thoroughly rinsed in PBS after each staining step, mounted onto glass slides, and coverslipped using prolong gold antifade mounting medium (Thermo Fisher Scientific). Sections labeled with the chromogen were counterstained with Nissl (cresyl violet), dehydrated using ethanol, and coverslipped using Permount mounting medium.

Image analysis. For high-magnification micrographs and cell count analyses, images were acquired as stacks using a SP6 confocal microscope (Leica Microsystems) at $63 \times$, deconvolved (AutoQuant X2, MediaCybernetics), and visualized using Imaris software (Bitplane). Processed image stacks were imported into ImageJ (Fiji version $1.51 \mathrm{~g}$, National Institutes of Health), and colocalization and cell counting analyses were performed using the Cell Counter plugin. Retrogradely labeled neurons from the VTA/SN were defined as cells containing retrobead puncta. A total of 3 or 4 image stacks were used to count colabeled cells for each animal. To quantify retrobead labeling density, a single image was extracted from the middle of each image stack and ROIs were drawn around each triple-labeled neuron. ROIs were then superimposed onto a thresholded image containing only the retrobead signal. Individual spots within each ROI were counted manually to determine the number of retrobead puncta per neuron. For virus and cannula placement verification and lowmagnification micrographs, images were acquired using a digital camera (Canon EOS Rebel T3) mounted on an Olympus BX40 microscope, and images were stitched together using Photoshop (Adobe).

Self-administration. D1-Cre rats and WT Long-Evans littermates were implanted with an indwelling jugular vein catheter. Rats received ketorolac ( $2 \mathrm{mg} / \mathrm{kg}$, i.p.) and cephazolin $(200 \mathrm{mg} / \mathrm{kg}$, i.p.) perioperatively and were allowed to recover for at least $5 \mathrm{~d}$ after surgery. To facilitate acquisition of cocaine selfadministration, rats were food-deprived overnight and trained $(2 \mathrm{~h})$ to lever press for food pellets. The following day, rats began a $12 \mathrm{~d}$ cocaine self-administration training regimen during which active lever presses were reinforced with the intravenous delivery of $0.2 \mathrm{mg}$ of cocaine in $50 \mu \mathrm{l}$ sterile saline $(\sim 0.5 \mathrm{mg} / \mathrm{kg} /$ infusion) paired with the presentation of a response contingent compound cue (tone + light). Presses on the inactive lever were without consequences and served as a control for motor activity and nonspecific responding. Immediately following self-administration, rats underwent at least $10 \mathrm{~d}$ of extinction train-

low retrograde retrobead transport into D1-MSNs projecting to the VP and VTA/SN. D1T, D1-tdTomato; RB, retrobeads. Scale bar, $10 \mu \mathrm{m}$. $\boldsymbol{H}$, Most collateralizing D1-MSNs contained a relatively low number of retrobead puncta, indicating sparse innervation of the VTA/SN. ${ }^{*} p<0.05$ comparing NAcore bin 10 with all other bins. ${ }^{+} p<0.05$ comparing NAshell bin 10 with bin $20-25$ and $35-45 . n=3$ mice per group. 
A

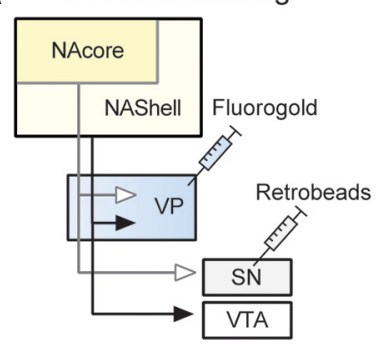

D

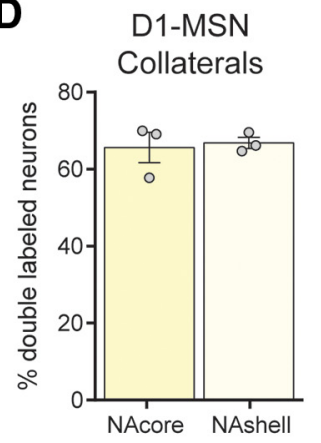

B

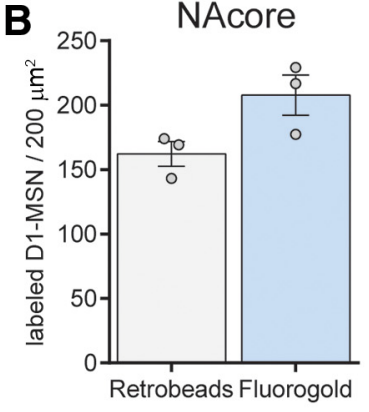

E

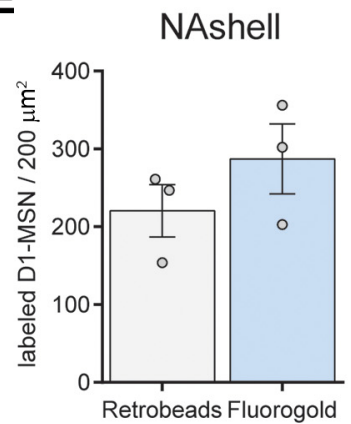

C

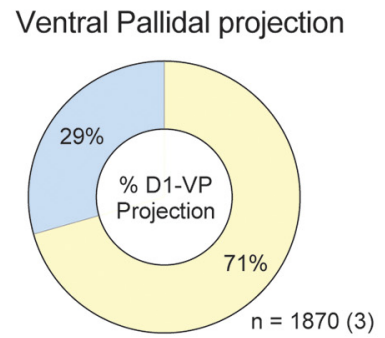

SN and VP (double labeled)

VP projection (fluorogold only)

$\mathbf{F}$
Substantia Nigra projection

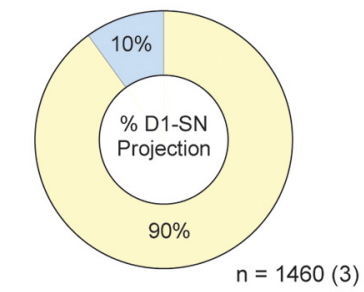

$\square$ VP and SN (double labeled)

$\square$ SN projection (retrobeads only)

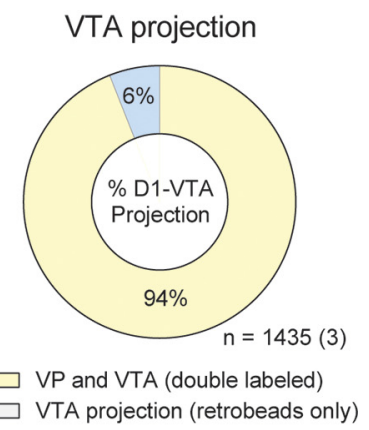

Figure 2. NAC D1-MSNs collateralize extensively between the VP and VTA/SN A, Schematic overview of the tracing experiment conducted in D1-tdTomato mice. FG was deposited in the medial or lateral VP, and retrobeads were either pressure-injected into the VTA or into the medial SN. $\boldsymbol{B}, \boldsymbol{E}$, Equal numbers of FG and retrobead retrogradely labeled neurons were found within the NAcore $(\boldsymbol{B})$ and NAshell $(\boldsymbol{E})$. C, Breakdown of the percentage of collateralizing neurons in the ventral pallidal and SN projection from the NAcore. $\boldsymbol{D}$, NAcore and NAshell contain equal proportions of collateralizing neurons. $\boldsymbol{F}$, Relative proportions of collateralizing neurons in the ventral pallidal and VTA pathways from the NAshell. Numbers indicate total number of cells (and animals).

ing in the same chambers, during which presses on either lever were without programmed consequences. Following extinction training, rats were tested during cue-induced reinstatement tests, wherein the drugpaired cues, but not cocaine itself, were returned to each active lever press. To facilitate drug seeking during reinstatement, $5 \mathrm{~min}$ into the session all rats received a noncontingent cue presentation. Each rat received both vehicle and $\mathrm{CNO}$ treatment, and was given at least $2 \mathrm{~d}$ of extinction training in between reinstatement tests. Rats were counterbalanced based on self-administration and extinction behavior, and no differences were observed between these groups before testing. Following cue-induced reinstatement tests, rats underwent two additional cocaineprimed reinstatement tests where they received an intraperitoneal injection of cocaine $(10 \mathrm{mg} / \mathrm{kg})$ immediately before a regular extinction session.

Chemogenetics. During catheter implantation, to target D1-MSN and D1-VP projections, D1-Cre rats were injected with a Cre-recombinasedependent vector carrying the inhibitory designer receptor exclusively activated by designer drugs (DREADDs) hM4Di (Gi-DREADD; AAV2hSyn-DIO-hM4Di; AddGene: 44362-AAV2; titer: $4.6 \times 10^{12} \mathrm{GC} / \mathrm{ml}$ ) into the NAcore (AP: 1.6; ML: 2.8 ; DV: -7 , angle: $10^{\circ}$ ). Only NAcore D1-MSNs project to the SN (Kupchik et al., 2015). Therefore, to target the D1-SN pathway, WT littermates were injected with a pan-neuronal vector carrying hM4D (AAV2-hSyn-hM4Di; University of North Carolina Vector Core; titer: $\left.2.6 \times 10^{12} \mathrm{GC} / \mathrm{ml}\right)$. Rats were implanted with chronic guide cannulae above the VP (AP: -0.2 ; ML: 2.3 ; DV: 6$)$ and SN (AP: -5.2 ; ML: $3.1 ; \mathrm{DV}:-5.5$, angle: $10^{\circ}$ ) held into place by dental acrylic and jeweler screws anchored in the skull. Cannulae (Plastics One) were fitted with dummy injectors to prevent debris from entering the cannulae. At $15 \mathrm{~min}$ before testing, rats received intraperitoneal $(10 \mathrm{mg} / \mathrm{kg})$ or intracranial injections of $\mathrm{CNO}(1 \mathrm{nmol} ; 500 \mathrm{nl} /$ side $)$ over 2 min using 33 gauge microinjector needles (Plastics One) that extended $2 \mathrm{~mm}$ from the tip of the cannulae. Following the microinfusion, cannulae were left in place for 2 additional minutes to allow for the diffusion of the drug.

Statistics. All data are presented as mean \pm SEM. Statistical analyses were performed using Prism (GraphPad; version 6.2), and outliers were removed using the ROUT module set at 1 . This analysis resulted in the removal of 5 rats that were entered into the behavioral studies. In addi- tion, 2 rats were excluded because they did not reinstate following a vehicle microinjection, and 3 rats were excluded for misplaced cannulae. Student's $t$ tests and $\chi^{2}$ tests were used for tracing studies. One-way and two-way repeated measures ANOVA with Greenhouse-Geisser correction and Neumann-Keuls post hoc tests were used for behavioral data and puncta analysis as specified in Results. Statistical significance was set at 0.05 .

\section{Results}

\section{NAc D1-MSNs collateralize into the VP and ventral mesencephalon}

To investigate whether and to what extent D1-MSN projection neurons collateralize between the VP and VTA/SN, we unilaterally injected two different retrograde chemical tracers into these structures in transgenic D1-tdTomato reporter mice (Fig. $1 A$ ) and quantified the amount of overlap in tracer uptake into accumbens D1-MSN. Because NAcore and NAshell subregions innervate distinct subareas of the VP and the ventral mesencephalon (Heimer et al., 1991), injections were placed at different coordinates along the mediolateral axis for both the VP and ventral mesencephalon. D1-MSN collaterals originating from the NAcore were targeted by injecting tracers into the medial SN and dorsolateral VP, whereas collaterals originating from NAshell neurons were studied by microinjecting tracer into the VTA and medial VP. To limit the amount of tracer uptake by fibers of passage in the VP, we iontophoretically deposited the charged tracer FG in the VP using small $(\sim 15-20 \mu \mathrm{m}$ diameter $)$ tipped glass micropipettes (Lu et al., 1998). Because very few NAc fibers pass through the VM (Heimer et al., 1991), we pressure-injected retrobeads into the VTA or medial SN. After $10 \mathrm{~d}$ of retrograde tracer transport into NAc neurons, we perfused the animals and quantified the amount of overlap of FG and retrobead tracers in D1-MSN of D1-tdTomato reporter mice (Fig. 1). Although we found dense labeling of FG in the NAc (Fig. $1 F)$, retrobead label- 
A
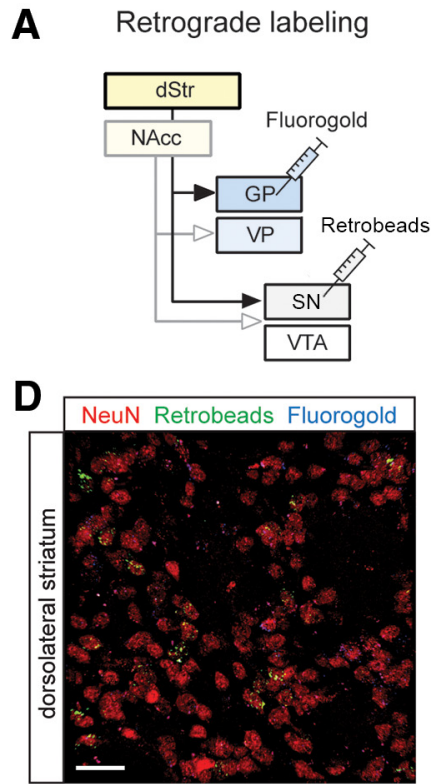

G

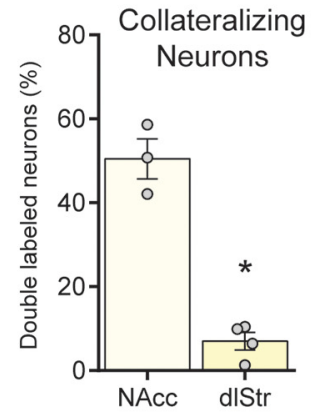

B

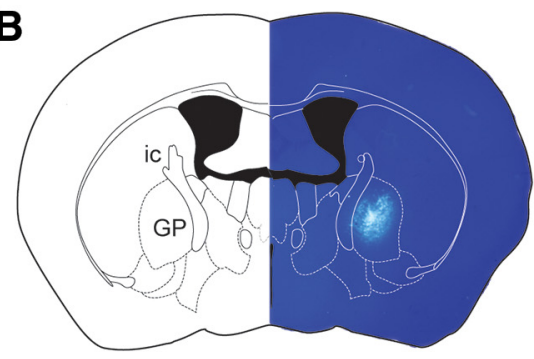

$\mathbf{E}$

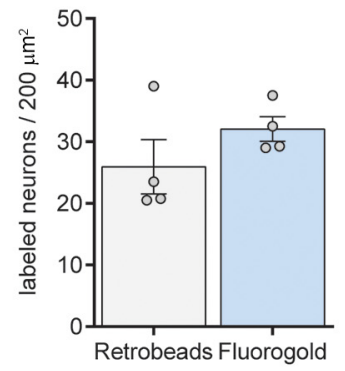

H Nucleus Accumbens

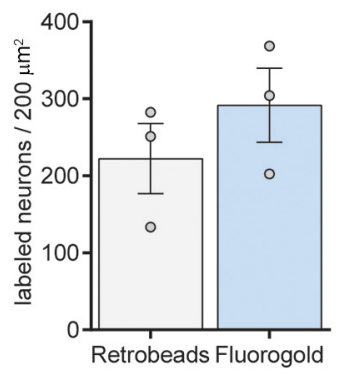

C

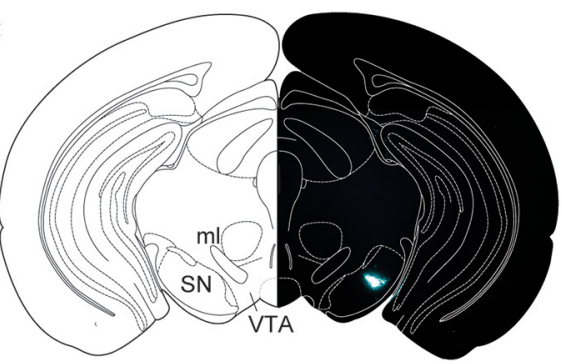

F Globus Pallidus projection

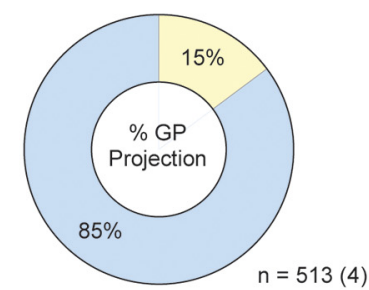

$\square \mathrm{SN}$ and GP (double labeled) $\square$ GP projection (fluorogold only)

I Ventral Pallidal projection

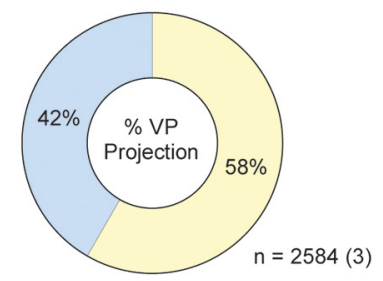

$\square$ VP and VTAVSN (double labeled) $\square$ VP projection (fluorogold only)
Substantia Nigra projection

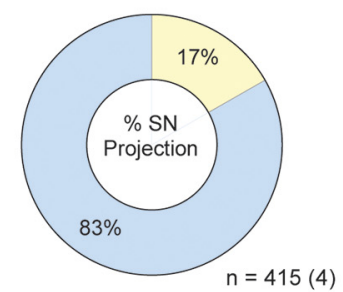

$\square$ SN projection (retrobeads only)

VTA/SN projection

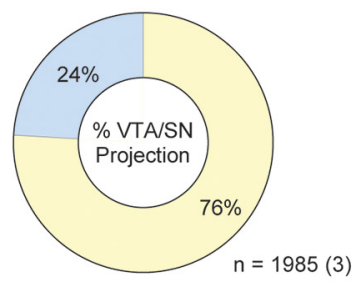

VP and VTA/SN (double labeled) VTA/SN projection (retrobeads only) $\square$ GP and SN (double labeled)

Figure 3. NAC MSNs collateralize more extensively than dorsolateral striatum MSN. A, Schematic overview of the tracing experiment conducted in WT mice. FG was deposited in the VP or GP, and retrobeads were either pressure-injected into the VTA or into the lateral SN. $\boldsymbol{B}$, FG deposit in the GP. C, Retrobead injection in the lateral SN. D, Retrogradely labeled dorsolateral striatum neurons containing retrobeads and/or FG. Neurons were counterstained using NeuN. Scale bar, $20 \mu \mathrm{m}$. $\boldsymbol{E}, \boldsymbol{H}$, Equal numbers of retrogradely labeled neurons containing retrobeads or FG in both the dorsolateral striatum $(\boldsymbol{E})$ and the NAc $(\boldsymbol{H})$. $\boldsymbol{F}$, Breakdown of the percentage of collateralizing neurons in the GP and SN projections from the dorsolateral striatum. $\boldsymbol{G}$, NAc neurons collateralize significantly more as evidenced by a larger percentage of double-labeled neurons. ${ }^{*} p<0.001$ (Student's $t$ test). I, Relative proportions of collateralizing neurons in the ventral pallidal and VTA/SN pathways from the NAc. Numbers indicate total number of cells (and animals).

ing was more variable, perhaps indicating variability in D1-MSN terminal density within the VTA/SN (Fig. 1E, G,H; two-way repeated-measures ANOVA main effect across bins, $F_{(8,32)}=$ $11.47, p<0.001$ ). However, overall a similar number of D1MSNs were labeled with FG and retrobeads, suggesting similar uptake rates of the two tracers between the VP and VTA/SN (Fig. $2 \mathrm{~B}, E$ ). Surprisingly, D1-MSNs in both NAcore and NAshell heavily collateralized between the VP and VTA/SN. A substantial number of retrogradely labeled D1-MSNs contained both tracers in the NAcore $(65.6 \pm 3.9 \%$, mean \pm SEM) and NAshell $(66.8 \pm 1.4 \%)$. No difference was observed in the percentage of double-labeled neurons between these structures (Fig. 2D). We also calculated the proportion of collateralizing neurons in the D1-VP or D1-VTA/SN pathway by expressing the number of double-labeled neurons as a fraction of all neurons containing FG (VP-projecting) or retrobeads (VTA/SN-projecting; Fig. 2C,F). In the NAshell, 94\% of D1MSNs that project to the VTA collateralize into the VP, and $70 \%$ of D1-MSNs projecting to VP send collaterals to the VTA (Fig. 2C). Similarly, in the NAcore, $90 \%$ of SN-projecting D1MSNs collateralize into the VP, and $71 \%$ of VP-projecting D1-MSNs collateralize to the SN (Fig. $2 F$ ). A $\chi^{2}$ analysis over the fraction of collaterals of D1-MSNs projecting to the VP did not reveal any differences between NAcore and NAshell. By contrast, the D1-SN projection from the NAcore contained more VP-projecting collaterals than the D1-VTA projection from the NAshell (Fig. $2 C, F ; \chi^{2}=15.63, p<0.001$ ).

\section{NAc MSNs collateralize more extensively than dorsolateral striatum MSNs}

Dorsal striatal projections to the midbrain passing through the GP are known to establish sparse synaptic contacts onto local GP neurons, and the extent of collateralization changes under specific conditions (Kawaguchi et al., 1990; Cazorla et al., 2014). To investigate whether and to what extent neurons in the dorsal striatum collateralize between these output structures in naive animals, we iontophoretically deposited FG in the GP, and pressure-injected retrobeads in the lateral SN of WT mice (Fig. $3 B, C)$. As a comparison and in an attempt to corroborate the NAc data (Fig. 2), we also injected tracers in the VP and VTA/SN of WT mice. Although we observed fewer overall labeled neurons in the dorsolateral striatum, the NAc and the dorsolateral striatum each contained equal numbers of neurons labeled with retrobeads or FG, indicating effective retrograde transport of these tracers into neurons from both regions (Fig. $3 E, H$ ). In concordance with the experiment above using the transgenic 
A
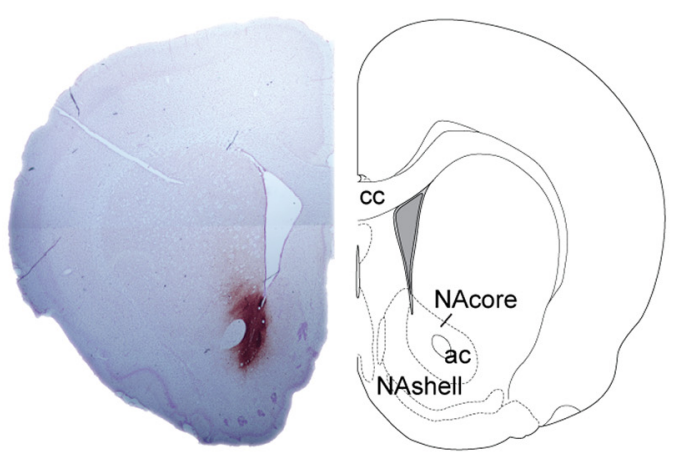

B

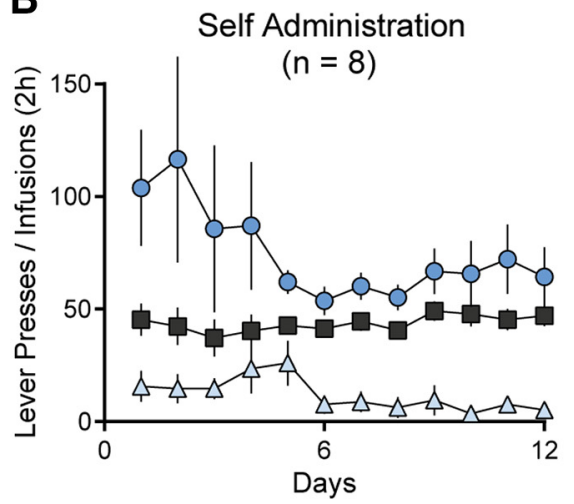

Extinction

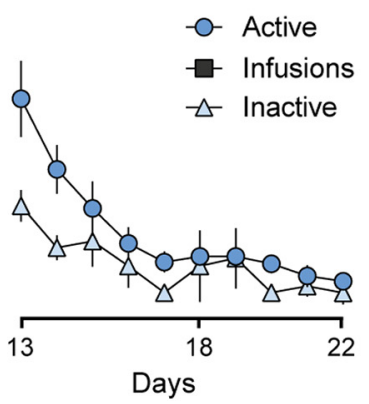

C Cue-Induced Reinstatement

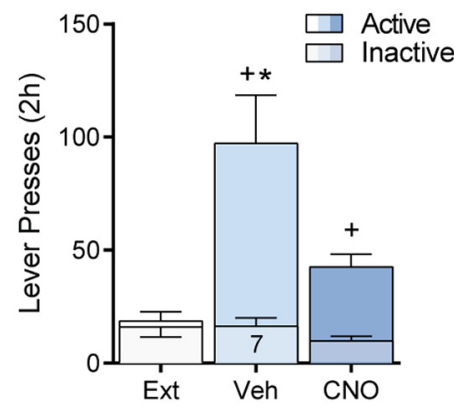

D Cocaine-Primed Reinstatement

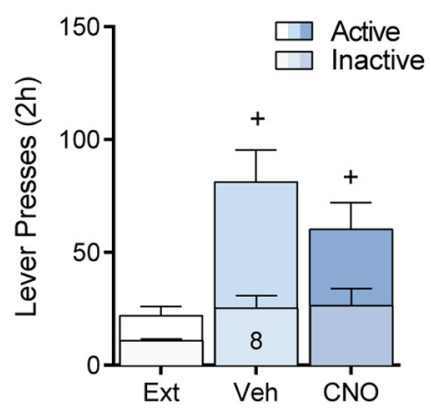

Figure 4. NAcore D1-MSN negatively regulate cue-induced reinstatement of cocaine seeking. A, Micrograph showing NAcore D1-MSN infected with Gi-DREADD. Image counterstained with Niss Istain (cresyl violet). B, Self-administration and extinction of rats. C, Inhibiting D1-MSN with systemic CNO (10 mg/kg, i.p.) significantly reduced cue-induced cocaine seeking. D, Inhibiting D1-MSN did not affect cocaineprimed reinstatement of drug seeking ( $n$ shown in bar). ${ }^{*} p<0.05$ comparing vehicle and $\mathrm{CNO}$-treated rats. ${ }^{+} p<0.05$ comparing reinstatement to extinction.

D1-tdTomato mice, we observed a substantial amount of neurons $\left(\mathrm{NeuN}^{+}\right.$cells) that collateralized between the VP and VTA/SN in the NAc of WT mice (Fig. $3 G$ ). Approximately half of all retrogradely labeled NAc neurons $(50.5 \pm 4.8 \%)$ contained both retrobeads and FG, presumably corresponding to the D1-MSNs because few or no D2-MSNs project to the ventral mesencephalon (Lu et al., 1998; Kupchik et al., 2015). By contrast, very few dorsolateral striatum neurons were doublelabeled (Fig. 3G; $7.0 \pm 2.1 \%$ ), and an unpaired Student's $t$ test revealed that the percentage of double-labeled neurons in the NAc was higher compared with the dorsolateral striatum (Fig. $\left.3 G ; t_{(5)}=9.26, p<0.001\right)$. These results suggest that, in contrast to ventral striatal accumbens neurons, dorsal striatopallidal and striatonigral projecting neurons collateralize to a much lesser extent. We also calculated the amount of collateralization for each pathway independently, which matched our previous observations for the NAc (Fig. 3I). By contrast, in the dorsal striatopallidal and striatonigral projection, a much smaller fraction of the neurons collateralized between these output structures (Fig. 3F; 15\% and 17\%, respectively). $\chi^{2}$ tests comparing the proportion of collateralizing neurons revealed differences in the striatopallidal $\left(\chi^{2}=369.1, p<\right.$ $0.001)$ and striatonigral pathway $\left(\chi^{2}=568.0, p<0.001\right)$ between the NAc and dorsolateral striatum.

\section{D1-MSN in the NAcore are necessary for cued cocaine seeking during reinstatement}

Previous studies indicate that activity in striatopallidal projection neurons from the NAcore is necessary for reinstated cocaine seeking (McFarland and Kalivas, 2001; Stefanik et al., 2013). This effect is mediated by D1-MSNs and dependent on downstream activity in the VP (Heinsbroek et al., 2017). However, given that a majority of NAcore D1-MSNs collateralize between the VP and $\mathrm{SN}$, previous studies using pharmacological or optogenetic methods of inhibition could not distinguish between D1-MSNs driving relapse through effects in either of these output structures or via coordinated activity in both. Although stimulating D1MSNs is sufficient to augment reinstatement of cocaine seeking in transgenic D1-Cre mice, inhibiting D1-MSNs did not affect reinstatement because of low rates of responding in mice compared with rats (Heinsbroek et al., 2017). To circumvent this problem, we used transgenic D1-Cre rats to study the role of NAcore D1-MSN using an inhibitory chemogenetic approach (Gi-DREADD; Fig. 4A). Following an initial brief food training session, rats underwent $12 \mathrm{~d}$ of self-administration and $10 \mathrm{~d}$ of extinction (Fig. 4B). Thirty minutes before cue- and cocaineprimed reinstatement tests, rats received intraperitoneal injections of CNO to inhibit D1-MSN activity in the NAcore. As expected, inhibiting the activity of D1-MSN significantly reduced responding on the active lever during cue-induced cocaine seeking (Fig. 4C; repeated-measures ANOVA, $F_{(1.89,13.2)}=16.5, p<$ $0.001)$. However, inhibiting D1-MSNs did not alter reinstatement following a priming injection of cocaine (Fig. $4 D$; repeatedmeasures ANOVA, $\left.F_{(1.95,13.6)}=13.79, p<0.001\right)$. Inactive lever pressing was not affected by either $\mathrm{CNO}$ or reinstatement (Fig. $4 C, D)$.

D1-MSN projections to the VP are necessary for cued cocaine seeking during reinstatement

To selectively inhibit projections from the NAcore to the VP without affecting fibers of passage or neural activity in the SN through collaterals, we used the Gi-DREADD and CNO micro- 
A

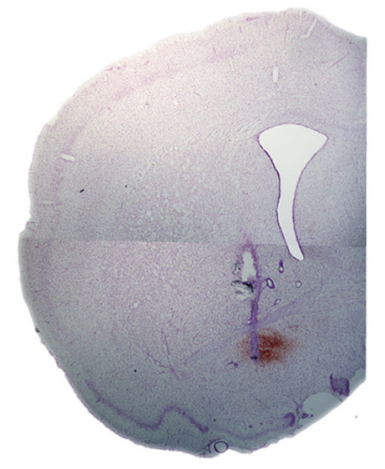

B
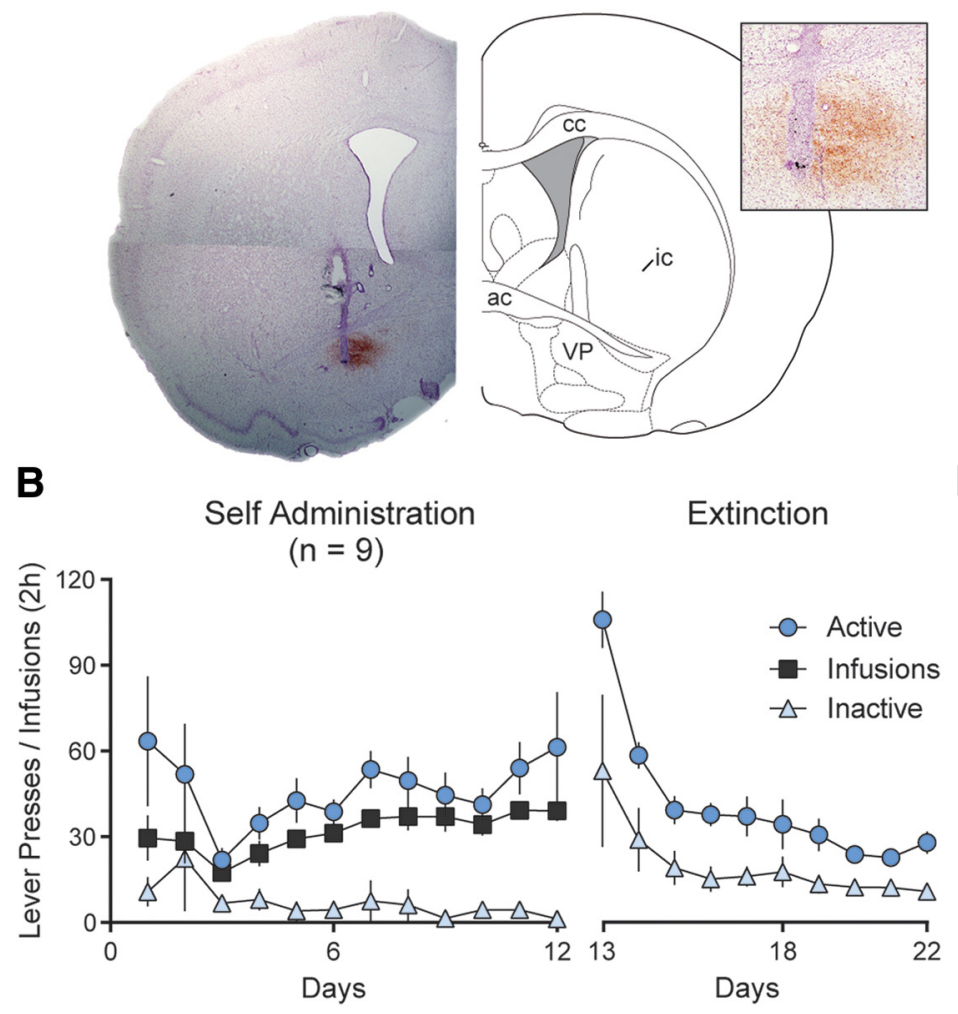

C

D

\section{Cocaine-Primed Reinstatement}

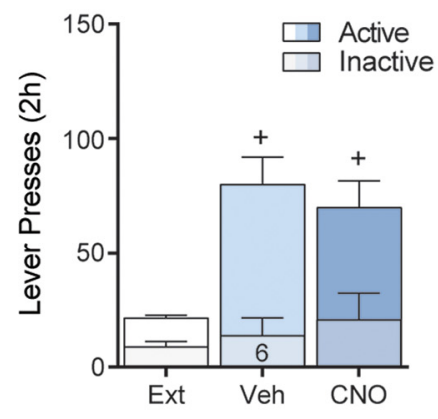

Figure 5. NAcore D1-VP projections negatively regulate cue-induced reinstatement of cocaine seeking. $\boldsymbol{A}$, Micrograph showing cannula tip and needle tract in the terminal field of the D1-VP projection. Inset, High-magnification micrograph showing terminal field and needle tip location. B, Self-administration and extinction of rats infected with Gi-DREADD in D1-MSN and implanted with guide cannulae above the VP. C, Inhibiting D1-VP with CN0 microinjected in the VP $(0.5 \mathrm{nmol} / 500 \mathrm{nl} /$ side) significantly reduced cue-induced cocaine seeking. $D$, Inhibiting D1-VP projections did not affect cocaine-primed reinstatement of drug seeking ( $n$ shown in bar). ${ }^{*} p<0.05$ comparing vehicle (aCSF) and CN0-treated rats. ${ }^{+} p<0.05$ comparing reinstatement to extinction.

injections to inhibit local neurotransmitter release in the VP (Mahler et al., 2014; Roth, 2016; Gallo et al., 2018). Gi-coupled G-protein coupled receptor signaling directly interferes with the synaptic vesicle release protein SNAP-25 to block vesicular release (Blackmer et al., 2001), and completely inhibits optically evoked GABA release from D1-MSN terminals in the VP (Heinsbroek et al., 2017). Following self-administration and extinction training (Fig. 5B), D1-Cre rats were microinjected 15 min before reinstatement tests with $\mathrm{CNO}(1 \mathrm{nmol})$ through chronically implanted VP guide cannulae. CNO significantly reduced active lever responding during cue-induced reinstatement of cocaine seeking (Fig. $5 \mathrm{C}$; repeated-measures ANOVA, $\left.F_{(1.20,9.57)}=17.3, p<0.01\right)$ but did not alter active lever responding during cocaine-primed reinstatement (Fig. 5D; repeated-measures ANOVA, $\left.F_{(1.76,8.82)}=11.6, p<0.01\right)$. Neither $\mathrm{CNO}$ treatment nor reinstatement altered inactive lever responding (Fig. 5C,D).

\section{D1-MSN projections to the SN do not affect cocaine seeking during reinstatement}

We next sought to investigate the role of striatonigral D1-MSN projections during reinstated cocaine seeking. Because only NAcore D1-MSNs innervate SN neurons (Kupchik et al., 2015), we transfected NAcore MSNs of WT D1-Cre littermates with the Gi-DREADD using a pan-neuronal promotor. Afterward, rats were implanted with cannulae aimed at the ventromedial part of the $\mathrm{SN}$ to target the NAcore D1-MSN terminals innervating this structure (Fig. 6A) (Heimer et al., 1991). After self-administration and extinction (Fig. $6 B$ ), $\mathrm{CNO}$ was microinjected into the $\mathrm{SN}$ before reinstatement tests. $\mathrm{CNO}$ did not alter active lever responding during cue-induced reinstatement of cocaine seeking (Fig. 6C; repeatedmeasures ANOVA, $\left.F_{(1.95,13.7)}=7.85, p<0.01\right)$ or cocaine-primed reinstatement (Fig. $6 D$; repeated-measures ANOVA, $F_{(1.63,8.16)}=$ $12.3, p<0.01)$. Furthermore, inactive lever pressing did not change during either test (Fig. 6C,D).

\section{Discussion}

It is established that D1-MSNs in the NAc project to both the VTA/SN and the VP (Robertson and Jian, 1995; Bock et al., 2013; Smith et al., 2013; Francis et al., 2015; Kupchik et al., 2015; Matsui and Alvarez, 2018). Because the striatomesencephalic D1VTA/SN pathway passes through the VP, it has been assumed that D1-VP projections consist of trespassing axons that collateralize onto local VP neurons (Matsui and Alvarez, 2018). We confirmed this assumption by finding that a majority of NAc D1-MSNs collateralize between the VTA/SN and VP. Furthermore, we observed that neurons in the NAc collateralize to a much greater extent than neurons in the dorsolateral striatum. We also found that D1-MSNs in the NAcore are necessary for driving cue-induced reinstatement, but not cocaine-primed reinstatement, of cocaine seeking. Although NAcore D1-MSNs extensively collateralize between the VP and SN, we demonstrated that only D1-VP projections, and not D1-SN projections, are necessary for cue-induced reinstatement of cocaine seeking. These 
A
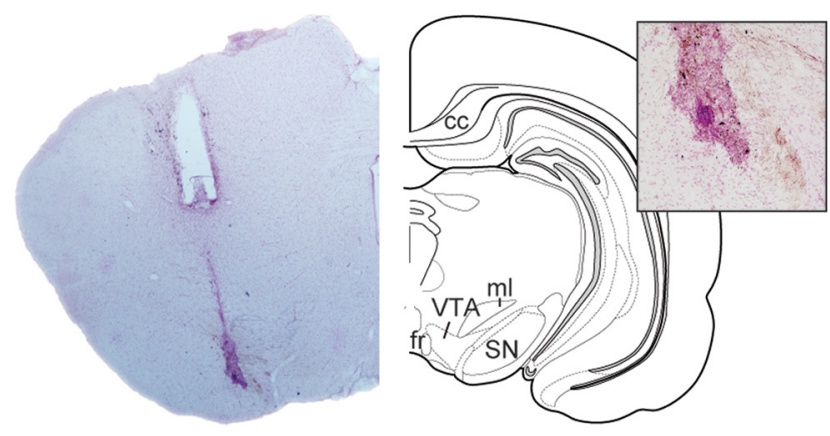

B

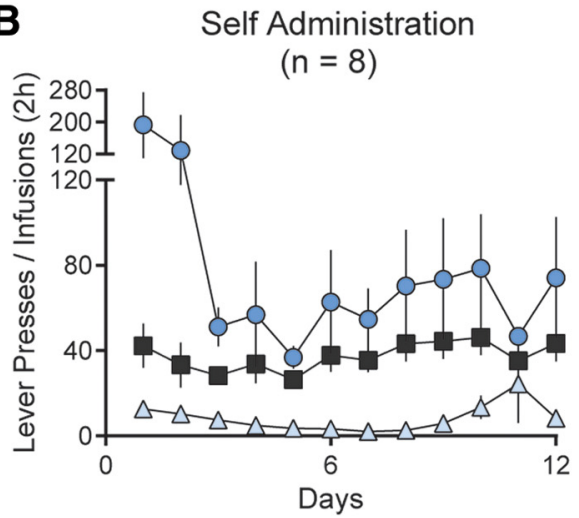

C

Cue-Induced Reinstatement

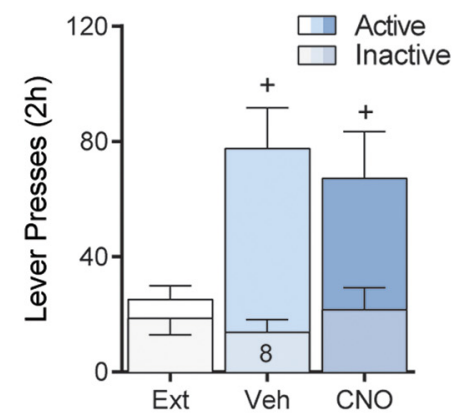

D

Cocaine-Primed Reinstatement

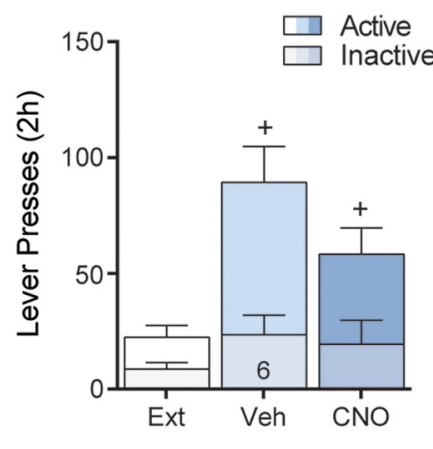

Figure 6. NAcore D1-MSN projections to the SN do not affect cue-induced or cocaine primed reinstatement of cocaine seeking. $\boldsymbol{A}$, Micrograph showing cannula and micro injector needle tract into the terminal field of NAcore D1-MSN in the ventromedial SN. Inset, High-magnification micrograph of terminal field and needle location. $\boldsymbol{B}$, Self-administration and extinction of rats infected with Gi-DREADD in D1-MSN and implanted with cannula targeting the SN. C, Inhibiting D1-SN projections with intracranial microinjections of CN0 (0.5 $\mathrm{nmol} / 500 \mathrm{nl} / \mathrm{side}$ ) did not affect cue-induced reinstatement of cocaine seeking. $\boldsymbol{D}$, Inhibiting D1-SN projections did not affect cocaine-primed reinstatement of drug seeking ( $n$ shown in bar). ${ }^{+} p<0.05$ comparing reinstatement to extinction.

studies indicate that, although these projections largely arise from the same neurons, they have distinct effects on motivated behavior depending on the downstream projection area (Fig. 7).

\section{Direct and indirect projections}

Recent findings are giving rise to a more nuanced working model of information flow through the basal ganglia. For instance, there is substantial crosstalk between the canonically distinct (D1- or D2-MSN originating) direct and indirect pathways of the dorsal striatum at the level of the GP (Cazorla et al., 2014; Saunders et al., 2015). Furthermore, NAc D1- and D2-MSN projections to the VP interconnect at the level of the $\mathrm{VP}$, giving rise to both direct and indirect VP projections to the VTA/SN and thalamus/epithalamus (Robertson and Jian, 1995; Lu et al., 1998; Kupchik et al., 2015; Knowland et al., 2017). Our current findings add to this complexity by demonstrating that a majority of D1-MSNs collateralize into the VP and the VTA/ $\mathrm{SN}$. This appears to be unique to the ventral basal ganglia because $<10 \%$ of dorsolateral striatal D1-MSNs collateralize to both the GP and SN.

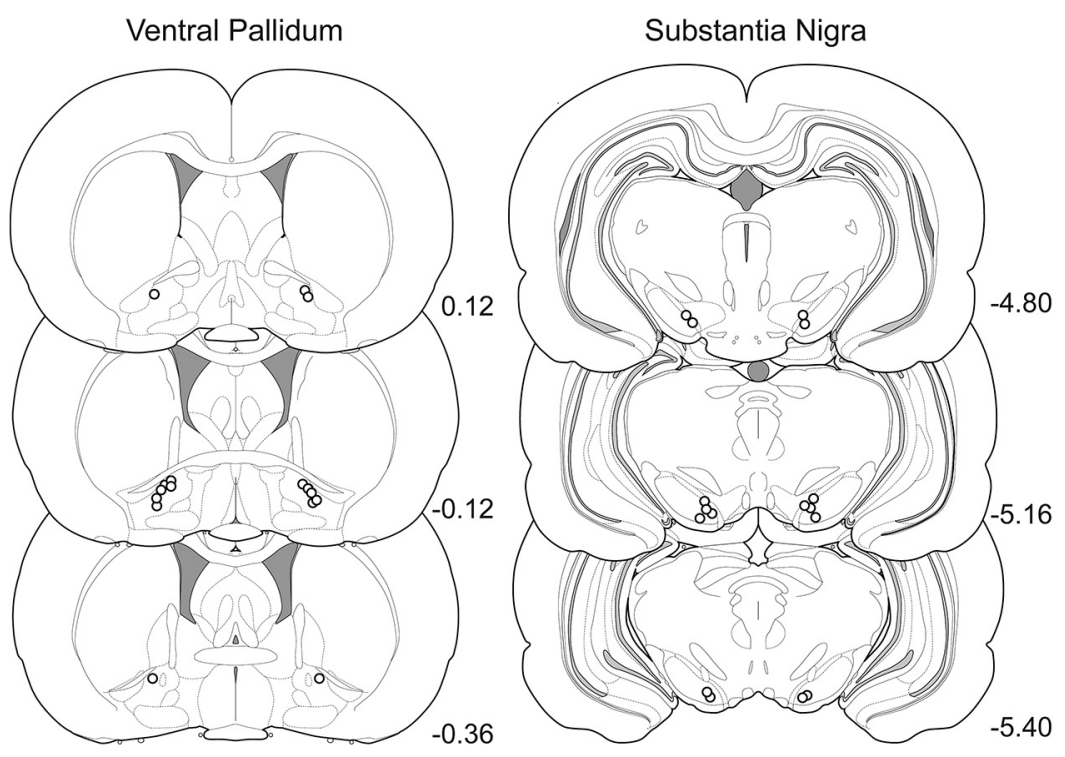

Figure 7. Location of needle tips in the VP and SN for intracranial microinjection experiments.

Comparing the NAcore and NAshell MSN projections

We observed equal numbers of collateralizing D1-MSNs in the NAcore and NAshell but found that a larger proportion of neurons in the NAcore D1-SN pathway collateralize to the VP compared with those in the NAshell D1-VTA pathway. The functional implications of this observation warrant further investiga- 
tion, given that D1-MSNs in NAcore and NAshell projecting to the VP likely convey distinct motivated information (Floresco, 2015). For instance, NAcore D1-MSNs are sufficient for cueinduced reinstatement of cocaine seeking (Heinsbroek et al., 2017), and the combined D1- and D2-MSN NAcore projection to the VP regulates reinstatement induced by combined cocaine cues and cocaine priming injection (Stefanik et al., 2013). By contrast, NAshell neurons are not necessary for combined cue and cocaine-induced reinstatement (McFarland and Kalivas, 2001). However, functional D1 or D2 receptors in the NAshell, but not in NAcore, are both sufficient and necessary for reinstatement to a cocaine priming injection (Anderson et al., 2003, 2006; Schmidt et al., 2006). Although more work is necessary, these findings suggest distinct roles for the NAcore and NAshell in reinstatement depending on whether drug seeking is elicited by drug-paired cues or priming drug injections. Combined with our current observations, it is tempting to speculate that D1-MSN projections from the NAshell to the VP and VTA are responsible for cocaine-primed reinstatement, and not cueinduced reinstatement of cocaine seeking. Alternatively, reinstatement could depend on activity in the D2-VP projection from the NAc. Arguing against a prominent role by activation of D2-MSN, cocaine inhibits D2-MSN activity and chemogenetically inhibiting D2-MSN potentiates reinstatement (Calipari et al., 2016; Heinsbroek et al., 2017). However, given the collateralization between D1- and D2-MSN in the NAc (Burke et al., 2017), it remains possible that D2-MSN activity may regulate reinstatement through collateral influences on D1-MSN.

Although we observed that NAcore and NAshell D1-MSNs strongly collateralize between the VP and VTA/SN, D1-MSNs projecting to the lateral hypothalamus (LH) and VTA from the NAshell comprise two largely nonoverlapping pathways (Gibson et al., 2018). In the D1-LH pathway, only $20 \%$ of D1-MSNs collateralized into the VTA (compared with $70 \%$ of the D1-VP pathway in our study), and only $10 \%$ of VTA projecting D1MSNs collateralized into the LH (compared with >90\%). These data suggest that the NAshell D1-LH projection is anatomically distinct from D1-VP and D1-VTA projections. In line with this idea, NAshell projections to the hypothalamus are thought to comprise a distinct basal ganglia output that functions to mediate the autonomous, somatomotor, and neuroendocrine responses of reward (Heimer et al., 1997). Furthermore, functionally distinct NAshell D1-LH and D1VTA pathways regulate different aspects of alcohol seeking. D1-VTA projections are necessary for context-induced reinstatement of alcohol seeking, whereas the D1-LH pathway mediates extinction (Marchant et al., 2009; Gibson et al., 2018).

Our experiments show that NAcore D1-MSN collaterals to the VP, not SN, drive drug seeking. However, it is possible that the $\sim 30 \%$ of D1-MSN afferents to the VP that do not appear to collateralize to the SN mediate cue-induced cocaine seeking. Exactly how the VP/SN collateralizing and VP only projecting D1MSNs integrate with the distinct output pathways of the VP and $\mathrm{SN}$ remains to be established. Furthermore, it needs to be determined whether these two populations of D1-MSN preferentially innervate one or another cell type in the VP.

\section{Cell type-specific targeting of VP and VTA/SN neurons}

Accumulating evidence suggests that D1-MSNs synapsing in the VP and ventral mesencephalon undergo similar adaptations in response to drug experience. For instance, NAshell D1-VP and D1-VTA synapses lose their ability to undergo synaptic plasticity (GABAergic LTP) after repeated noncontingent injections of cocaine due to a persistent potentiation of synaptic transmission in these synapses (Bocklisch et al., 2013; Creed et al., 2016). Because D1-MSN projections from the NAc to the lateral VTA preferentially target $\mathrm{GABA}_{\mathrm{A}}$ receptors onto GABAergic interneurons, augmentation of GABA release from D1-MSN afferents disinhibits VTA dopamine neurons (Bocklisch et al., 2013; Kupchik et al., 2015; Yang et al., 2018). D1-VTA projections originating from the medial NAshell also target accumbens-innervating dopamine neurons directly through $\mathrm{GABA}_{\mathrm{B}}$ receptors, and this pathway comprises a delayed negative feedback on mesolimbic dopamine signaling (Edwards et al., 2017; Yang et al., 2018). Therefore, some D1MSN projection neurons may form collaterals to signal delayed negative feedback, whereas other D1-MSNs may collateralize to amplify a signal in both the VP and VTA/SN.

It remains to be established what types of neurons in the VP are innervated by D1-VP projections (Root et al., 2015). Given that the majority of VP neurons are GABAergic projection neurons, and that many of these neurons directly innervate dopamine neurons in the VTA and SN, D1-VP projections may indirectly disinhibit dopamine neurons downstream (Floresco et al., 2003; Hjelmstad et al., 2013; Chang and Grace, 2014; Mahler et al., 2014; Root et al., 2015). In addition to these GABAergic neurons, a substantial proportion of VP neurons are glutamatergic, and at least a subset of glutamatergic VP neurons that coexpress parvalbumin are equally innervated by NAc D1-MSN and D2-MSN (Hur and Zaborszky, 2005; Geisler et al., 2008; Knowland et al., 2017; Faget et al., 2018; Tooley et al., 2018). Thus, additional research is necessary to identify the distinct subtypes of neurons that are innervated by D1-VP and D1-VTA/SN projections.

\section{Technical considerations}

We used a chemogenetic strategy to selectively inhibit D1-MSN cell bodies and axon terminals, and it is important to note the limitations of this approach (Mahler et al., 2014; Roth, 2016; Mahler and Aston-Jones, 2018). CNO, the ligand used to activate Gi-DREADD, is metabolized into clozapine by the liver, and clozapine is the main activator of DREADDs in the CNS following systemic CNO injections (Gomez et al., 2017; Mahler and AstonJones, 2018). Importantly, previous studies using equal or higher doses of systemic CNO report no nonspecific effects on reinstatement (Mahler et al., 2014; Augur et al., 2016). Similarly, previous studies found that CNO microinjected into the ventral mesencephalon, lateral septum, or VP does not affect reinstatement (Mahler et al., 2014; McGlinchey and Aston-Jones, 2018) or other motivated behaviors (Gallo et al., 2018).

We used WT littermates for targeting the D1-SN pathway because SN neurons only respond to optical stimulation of D1MSN terminals (Kupchik et al., 2015). However, retrograde labeling from $\mathrm{SN}$ reveals that $\sim 1 \%$ of NAcore neurons contain D2 receptor mRNA (Lu et al., 1998), which likely correspond to the $\sim 1.6 \%$ of NAcore neurons that express both D1 and D2 receptors (Thibault et al., 2013; Kupchik et al., 2015). Thus, a very small number of MSN-coexpressing D1/D2 receptors may innervate the ventral mesencephalon.

In conclusion, our results demonstrate that NAcore D1-MSN projections from the NAc collateralize between the VP and SN, and that these projections differentially regulate cocaine seeking during cue-induced reinstatement. These findings contribute to our understanding of the connectivity in ventral basal ganglia circuits and set the stage for further characterization of the roles 
these projections have relapse to drug seeking, and in regulated motivated behavior in general.

\section{References}

Anderson SM, Bari AA, Pierce RC (2003) Administration of the D1-like dopamine receptor antagonist SCH-23390 into the medial nucleus accumbens shell attenuates cocaine priming-induced reinstatement of drug-seeking behavior in rats. Psychopharmacology (Berl) 168:132-138.

Anderson SM, Schmidt HD, Pierce RC (2006) Administration of the D2 dopamine receptor antagonist sulpiride into the shell, but not the core, of the nucleus accumbens attenuates cocaine priming-induced reinstatement of drug seeking. Neuropsychopharmacology 31:1452-1461.

Augur IF, Wyckoff AR, Aston-Jones G, Kalivas PW, Peters J (2016) Chemogenetic activation of an extinction neural circuit reduces cue-induced reinstatement of cocaine seeking. J Neurosci 36:10174-10180.

Blackmer T, Larsen EC, Takahashi M, Martin TF, Alford S, Hamm HE (2001) G protein betagamma subunit-mediated presynaptic inhibition: regulation of exocytotic fusion downstream of $\mathrm{Ca}^{2+}$ entry. Science 292:293-297.

Bock R, Shin JH, Kaplan AR, Dobi A, Markey E, Kramer PF, Gremel CM, Christensen CH, Adrover MF, Alvarez VA (2013) Strengthening the accumbal indirect pathway promotes resilience to compulsive cocaine use. Nat Neurosci 16:632-638.

Bocklisch C, Pascoli V, Wong JC, House DR, Yvon C, de Roo M, Tan KR, Lüscher C (2013) Cocaine disinhibits dopamine neurons by potentiation of GABA transmission in the ventral tegmental area. Science 341: $1521-1525$.

Burke DA, Rotstein HG, Alvarez VA (2017) Striatal local circuitry: a new framework for lateral inhibition. Neuron 96:267-284.

Calipari ES, Bagot RC, Purushothaman I, Davidson TJ, Yorgason JT, Peña CJ, Walker DM, Pirpinias ST, Guise KG, Ramakrishnan C, Deisseroth K, Nestler EJ (2016) In vivo imaging identifies temporal signature of D1 and D2 medium spiny neurons in cocaine reward. Proc Natl Acad Sci U S A 113:2726-2731.

Cazorla M, de Carvalho FD, Chohan MO, Shegda M, Chuhma N, Rayport S, Ahmari SE, Moore H, Kellendonk C (2014) Dopamine D2 receptors regulate the anatomical and functional balance of basal ganglia circuitry. Neuron 81:153-164.

Chang CH, Grace AA (2014) Amygdala-ventral pallidum pathway decreases dopamine activity after chronic mild stress in rats. Biol Psychiatry 76: 223-230.

Creed M, Ntamati NR, Chandra R, Lobo MK, Lüscher C (2016) Convergence of reinforcing and anhedonic cocaine effects in the ventral pallidum. Neuron 92:214-226.

Edwards NJ, Tejeda HA, Pignatelli M, Zhang S, McDevitt RA, Wu J, Bass CE, Bettler B, Morales M, Bonci A (2017) Circuit specificity in the inhibitory architecture of the VTA regulates cocaine-induced behavior. Nat Neurosci 20:438-448.

Faget L, Zell V, Souter E, McPherson A, Ressler R, Gutierrez-Reed N, Yoo JH, Dulcis D, Hnasko TS (2018) Opponent control of behavioral reinforcement by inhibitory and excitatory projections from the ventral pallidum. Nat Commun 9:849.

Floresco SB (2015) The nucleus accumbens: an interface between cognition, emotion, and action. Annu Rev Psychol 66:25-52.

Floresco SB, West AR, Ash B, Moore H, Grace AA (2003) Afferent modulation of dopamine neuron firing differentially regulates tonic and phasic dopamine transmission. Nat Neurosci 6:968-973.

Francis TC, Chandra R, Friend DM, Finkel E, Dayrit G, Miranda J, Brooks JM, Iñiguez SD, O’Donnell P, Kravitz A, Lobo MK (2015) Nucleus accumbens medium spiny neuron subtypes mediate depression-related outcomes to social defeat stress. Biol Psychiatry 77:212-222.

Gallo EF, Meszaros J, Sherman JD, Chohan MO, Teboul E, Choi CS, Moore H, Javitch JA, Kellendonk C (2018) Accumbens dopamine D2 receptors increase motivation by decreasing inhibitory transmission to the ventral pallidum. Nat Commun 9:1086.

Geisler S, Marinelli M, Degarmo B, Becker ML, Freiman AJ, Beales M, Meredith GE, Zahm DS (2008) Prominent activation of brainstem and pallidal afferents of the ventral tegmental area by cocaine. Neuropsychopharmacology 33:2688-2700.

Gerfen CR, Surmeier DJ (2011) Modulation of striatal projection systems by dopamine. Annu Rev Neurosci 34:441-466.

Gerfen CR, Engber TM, Mahan LC, Susel Z, Chase TN, Monsma FJ Jr, Sibley
DR (1990) D1 and D2 dopamine receptor-regulated gene expression of striatonigral and striatopallidal neurons. Science 250:1429-1432.

Gibson GD, Prasad AA, Jean-Richard-Dit-Bressel P, Yau JO, Millan EZ, Liu Y, Campbell EJ, Lim J, Marchant NJ, Power JM, Killcross S, Lawrence AJ, McNally GP (2018) Distinct accumbens shell output pathways promote versus prevent relapse to alcohol seeking. Neuron 98:512-520.e6.

Gomez JL, Bonaventura J, Lesniak W, Mathews WB, Sysa-Shah P, Rodriguez LA, Ellis RJ, Richie CT, Harvey BK, Dannals RF, Pomper MG, Bonci A, Michaelides M (2017) Chemogenetics revealed: DREADD occupancy and activation via converted clozapine. Science 357:503-507.

Groenewegen HJ, Wright CI, Beijer AV, Voorn P (1999) Convergence and segregation of ventral striatal inputs and outputs. Ann N Y Acad Sci 877:49-63.

Haber SN (2011) Neuroanatomy of reward: a view from the ventral striatum. In: Neurobiology of sensation and reward (Gottfried JA, ed). Boca Raton, FL: CRC.

Heimer L, Zahm DS, Churchill L, Kalivas PW, Wohltmann C (1991) Specificity in the projection patterns of accumbal core and shell in the rat. Neuroscience 41:89-125.

Heimer L, Alheid GF, de Olmos JS, Groenewegen HJ, Haber SN, Harlan RE, Zahm DS (1997) The accumbens: beyond the core-shell dichotomy. J Neuropsychiatry Clin Neurosci 9:354-381.

Heinsbroek JA, Neuhofer DN, Griffin WC 3rd, Siegel GS, Bobadilla AC, Kupchik YM, Kalivas PW (2017) Loss of plasticity in the D2-accumbens pallidal pathway promotes cocaine seeking. J Neurosci 37:757-767.

Hjelmstad GO, Xia Y, Margolis EB, Fields HL (2013) Opioid modulation of ventral pallidal afferents to ventral tegmental area neurons. J Neurosci 33:6454-6459.

Hur EE, Zaborszky L (2005) Vglut2 afferents to the medial prefrontal and primary somatosensory cortices: a combined retrograde tracing in situ hybridization study [corrected]. J Comp Neurol 483:351-373.

Kawaguchi Y, Wilson CJ, Emson PC (1990) Projection subtypes of rat neostriatal matrix cells revealed by intracellular injection of biocytin. J Neurosci 10:3421-3438.

Knowland D, Lilascharoen V, Pacia CP, Shin S, Wang EH, Lim BK (2017) Distinct ventral pallidal neural populations mediate separate symptoms of depression. Cell 170:284-297.e18.

Kupchik YM, Brown RM, Heinsbroek JA, Lobo MK, Schwartz DJ, Kalivas PW (2015) Coding the direct/indirect pathways by D1 and D2 receptors is not valid for accumbens projections. Nat Neurosci 18:1230-1232.

Lu XY, Ghasemzadeh MB, Kalivas PW (1998) Expression of $\mathrm{D}_{1}$ receptor, $\mathrm{D}_{2}$ receptor, substance $\mathrm{P}$ and enkephalin messenger RNAs in the neurons projecting from the nucleus accumbens. Neuroscience 82:767-780.

Mahler SV, Aston-Jones G (2018) CNO evil? Considerations for the use of DREADDs in behavioral neuroscience. Neuropsychopharmacology 43 : 934-936.

Mahler SV, Vazey EM, Beckley JT, Keistler CR, McGlinchey EM, Kaufling J, Wilson SP, Deisseroth K, Woodward JJ, Aston-Jones G (2014) Designer receptors show role for ventral pallidum input to ventral tegmental area in cocaine seeking. Nat Neurosci 17:577-585.

Marchant NJ, Hamlin AS, McNally GP (2009) Lateral hypothalamus is required for context-induced reinstatement of extinguished reward seeking. J Neurosci 29:1331-1342.

Matsui A, Alvarez VA (2018) Cocaine inhibition of synaptic transmission in the ventral pallidum is pathway-specific and mediated by serotonin. Cell Rep 23:3852-3863.

McFarland K, Kalivas PW (2001) The circuitry mediating cocaine-induced reinstatement of drug-seeking behavior. J Neurosci 21:8655-8663.

McGlinchey EM, Aston-Jones G (2018) Dorsal hippocampus drives context-induced cocaine seeking via inputs to lateral septum. Neuropsychopharmacology 43:987-1000.

Robertson GS, Jian M (1995) D1 and D2 dopamine receptors differentially increase fos-like immunoreactivity in accumbal projections to the ventral pallidum and midbrain. Neuroscience 64:1019-1034.

Root DH, Melendez RI, Zaborszky L, Napier TC (2015) The ventral pallidum: subregion-specific functional anatomy and roles in motivated behaviors. Prog Neurobiol 130:29-70.

Roth BL (2016) DREADDs for neuroscientists. Neuron 89:683-694.

Saunders A, Oldenburg IA, Berezovskii VK, Johnson CA, Kingery ND, Elliott HL, Xie T, Gerfen CR, Sabatini BL (2015) A direct GABAergic output from the basal ganglia to frontal cortex. Nature 521:85-89.

Saunders A, Macosko EZ, Wysoker A, Goldman M, Krienen FM, de Rivera H, 
Bien E, Baum M, Bortolin L, Wang S, Goeva A, Nemesh J, Kamitaki N, Brumbaugh S, Kulp D, McCarroll SA (2018) Molecular diversity and specializations among the cells of the adult mouse brain. Cell 174:1015-1030.e16.

Schmidt HD, Anderson SM, Pierce RC (2006) Stimulation of D1-like or D2 dopamine receptors in the shell, but not the core, of the nucleus accumbens reinstates cocaine-seeking behaviour in the rat. Eur J Neurosci 23:219-228.

Scofield MD, Heinsbroek JA, Gipson CD, Kupchik YM, Spencer S, Smith AC, Roberts-Wolfe D, Kalivas PW (2016) The nucleus accumbens: mechanisms of addiction across drug classes reflect the importance of glutamate homeostasis. Pharmacol Rev 68:816-871.

Shuen JA, Chen M, Gloss B, Calakos N (2008) Drdla-tdTomato BAC transgenic mice for simultaneous visualization of medium spiny neurons in the direct and indirect pathways of the basal ganglia. J Neurosci 28:26812685.

Smith RJ, Lobo MK, Spencer S, Kalivas PW (2013) Cocaine-induced adaptations in D1 and D2 accumbens projection neurons (a dichotomy not necessarily synonymous with direct and indirect pathways). Curr Opin Neurobiol 23:546-552.

Stefanik MT, Kupchik YM, Brown RM, Kalivas PW (2013) Optogenetic evidence that pallidal projections, not nigral projections, from the nucleus accumbens core are necessary for reinstating cocaine seeking. J Neurosci 33:13654-13662.

Thibault D, Loustalot F, Fortin GM, Bourque MJ, Trudeau LE (2013) Evaluation of D1 and D2 dopamine receptor segregation in the developing striatum using BAC transgenic mice. PLoS One 8:e67219.

Tooley J, Marconi L, Alipio JB, Matikainen-Ankney B, Georgiou P, Kravitz AV, Creed MC (2018) Glutamatergic ventral pallidal neurons modulate activity of the habenula-tegmental circuitry and constrain reward seeking. Biol Psychiatry 83:1012-1023.

Tripathi A, Prensa L, Cebrián C, Mengual E (2010) Axonal branching patterns of nucleus accumbens neurons in the rat. J Comp Neurol 518:46494673.

Warming S, Costantino N, Court DL, Jenkins NA, Copeland NG (2005) Simple and highly efficient BAC recombineering using galK selection. Nucleic Acids Res 33:e36.

Yang H, de Jong JW, Tak Y, Peck J, Bateup HS, Lammel S (2018) Nucleus accumbens subnuclei regulate motivated behavior via direct inhibition and disinhibition of VTA dopamine subpopulations. Neuron 97:434-449.e4.

Yizhar O, Fenno LE, Davidson TJ, Mogri M, Deisseroth K (2011) Optogenetics in neural systems. Neuron 71:9-34. 